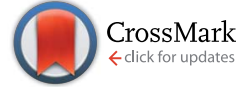

Cite this: RSC Adv., 2015, 5, 93818

\title{
Anticorrosion/antifouling properties of bacterial spore-loaded sol-gel type coating for mild steel in saline marine condition: a case of thermophilic strain of Bacillus licheniformis $\uparrow$
}

\author{
Ubong Eduok, ${ }^{a}$ Rami Suleiman, ${ }^{\text {b }}$ Jeanette Gittens, ${ }^{\mathrm{c}}$ Mazen Khaled, ${ }^{a}$ \\ Thomas J. Smith, ${ }^{c}$ Robert Akid, ${ }^{d}$ Bassam El Ali ${ }^{a}$ and Amjad Khalil ${ }^{\mathrm{e}}$
}

\begin{abstract}
This work reports the performance of a sol-gel type coating encapsulated with biofilm of inoculums of protective thermophilic strain of Bacillus licheniformis endospores isolated from the Gazan hot springs-Saudi Arabia for the inhibition of marine fouling and corrosion protection of S36-grade mild steel in $3.5 \mathrm{wt} \% \mathrm{NaCl}$ medium. In order to improve its anticorrosion properties, the hybrid sol-gel coating is further doped with zinc molybdate (MOLY) and zinc aluminum polyphosphate (ZAPP) pigments. Marine fouling study was conducted at the Arabia Gulf water of Half Moon Bay, Al-Khobar, Saudi Arabia for 10 weeks on the coated samples with and without the bacterial endospores. The assessment of fouling results reveals that the bacterial endospores possess antifouling potentials since it performed better compared to its abiotic counterpart within the immersion period of study due to their foul-releasing effect. Improved corrosion and fouling resistant in the presence of the bacterial endospores could be attributed to their multi-layered hydrophobic and antibiotic coating surface after bacterial encapsulation. Spores accumulation in the sol-gel coating altered the surface wetness thereby preventing the diffusion of corrosion molecules and ions through the bulk of the coating to the metal surface; this is evident in the trend of electrochemical coating resistance and capacitance. Confocal laser scanning fluorescence and scanning electron microscopies were employed to probe bacterial viability and surface micro-cracks inherent in the coating, respectively. This is the first report of axenic thermophilic strain of Bacillus licheniformis isolated from the Arabian Gulf with inhibiting potentials against corrosion and fouling of industrial steel.
\end{abstract}

Received 16th August 2015

Accepted 26th October 2015

DOI: $10.1039 / \mathrm{c} 5 \mathrm{ra16494j}$

www.rsc.org/advances

\section{Introduction}

Microbiologically-influenced corrosion (MIC) is one of the most aggressive types of corrosion affecting many metal structures and facilities, especially power plants, gas and oil pipelines, mining and chemical processing facilities. MIC is accelerated by the formation of corrosive and acidic biofilms on coated metal substrates by microorganisms such as sulfate-reducing bacteria (e.g. Desulfovibrio), creating surface cracks and

${ }^{a}$ Department of Chemistry, King Fahd University of Petroleum \& Minerals (KFUPM), Dhahran 31261, Saudi Arabia

${ }^{b}$ Center of Research Excellence in Corrosion, King Fahd University of Petroleum \& Minerals (KFUPM), Dhahran 31261, Saudi Arabia. E-mail: ramismob@kfupm.edu. sa; Fax: +966-13-8603996; Tel: +966-13-8607580

'Biomedical Research Centre, Sheffield Hallam University, Howard Street, Sheffield, S1 $1 W B, U K$

${ }^{d}$ Corrosion \& Protection Centre, School of Materials, University of Manchester, M13 9PL, UK

${ }^{e}$ Department of Biology, King Fahd University of Petroleum \& Minerals (KFUPM), Dhahran 31261, Saudi Arabia

$\dagger$ Electronic supplementary information (ESI) available. See DOI: 10.1039/c5ra16494j leading to stress corrosion. ${ }^{1}$ In the marine environment, attachment of a biofilm may increase the settlement of macrofouling organisms in a manner that, though this is dependent on chemical cues from the exopolymers and other microbially derived molecules in the film as well as associated organic and inorganic materials on the substrate. ${ }^{2}$ Biological fouling, or simply, biofouling, is the adhesion of stable biological growths (micro and macro) on submerged or unsubmerged surfaces of substrates, and it is directly related to the formation of biofilm on such wetted surfaces. These biofilms are polymeric matrices of biological cells and exudates, and their nature depends on the type of organism and colonies secreting them, composition and thickness of the biofilm. Biofilm secretion is the initiation stage of all biofouling processes, subsequently proceeded by different stages growth in succession. ${ }^{3}$ The effects of surface roughness of fouling-affected marine vessels and ship hulls cannot be overemphasized in terms of hydrodynamics. The presence of "hard" foulers such as adult barnacles and mussels initiates surface drag and sheer stress thereby reducing the speed and power of vessels, consequently wasting fuel. Depending on the growth pattern, micro and macro foulers may 
act as a barrier for the diffusion of ions and subsequently create differential aeration concentration cells on the surface of the vessel by decreasing the flow of localized oxygen and hence exacerbate corrosion. ${ }^{4}$

Several mitigation methods and procedures have been deployed for the control of MIC and fouling. ${ }^{5}$ Some of these control procedures involve biocidal chemical dispersion, conventional surface adhesion reduction against macro-foulers and other sophisticated methods that involve complementary modification of the substrates' surface prior to the adhesion of possible foulers, such as biocidal or low surface energy fouling release coatings. Historically, the easiest and cheapest method of preventing the growth of acidogenic biofilms is the use of biocides, e.g. tributyltin. Although such biocides are effective, they have widespread environmental toxicity and current legislation on environmentally-damaging chemicals prevents their use. ${ }^{6}$ Organotins were widely encapsulated into some polymer-based paints with self-polishing and self/controlledreleasing properties for marine vessels. ${ }^{7}$ The application of a control-release coating synthesized from polydimethylsiloxane crossed-linked with (heptadecafluoro-1,1,2,2-tetrahydrodecyl) triethoxysilane with reliable stability and its antifouling mechanism drawn from the formation of a stable fluorinated siliceous phase was reported by Berglin et al. (2003). ${ }^{8}$ Recent trends in the design of stable chemical mitigation systems have witnessed the fabrication of polymer "brushes", with unique chemical architectures and antifouling/antibiocorrosion mechanisms. These designs allow for the incorporation of antimicrobial and anticorrosive functional groups or moieties. ${ }^{9,10}$ Quintana et al. ${ }^{9}$ have recently reported antifouling applications of zwitterionic polymer brushes synthesized from the surface-initiated atom transfer radical polymerization of vinylimidazolium, vinylbenzene, sulfobetaine and methacrylamide. The surface bioactivity of these polymer brushes provided resistance to adhesion of the alga Amphora coffeaeformis and the barnacle Amphibalanus amphitrite. Unlike biocide-releasing systems, polymer brushes are multifunctional, with surface adhesion properties and many are non-leaching and non-toxic but are also unstable and relatively unavailable for surface bioactivity. The surface microstructures of marine vessels and boats vary depending of the metal substrates deployed for their fabrication, yet all are susceptible to biofouling. Metal surfaces and textures can be modified to mimic shark skin, with reduced wettability and a microstructured surface to deter fouling bioadhesion. Carman et al. ${ }^{11}$ have reported the design and surface topography modification with Sharklet $\mathrm{AF}^{\mathrm{TM}}$ bioengineered with ridges similar to sharks of the Chondrichthyes class. Compared to a polydimethylsiloxane elastomer coating, Sharklet AFTM demonstrated resistance to Ulva linza and endothelial cells from pig, hence served as an antifoulant. Some of these surface modifiers could be amphiphilic or hydrophilic and are commercially available, but their nanotopographies may be affected debris.

Organic-inorganic hybrid sol-gel thin films are promising alternatives to conventional primers and environmentally toxic chromate coatings for marine applications. Sol-gel coatings can be organically functionalized with new chemical groups that can further enhance coating/metal chemistry, adhesion, hydrolytic stability and even the hydrophobicity of coatings. Sol-gel processing has been employed in metal protection studies because of the abundance of simple alkoxysilanes, particularly the tetraoxy silicates and organically modified silicates precursors are widely used in the syntheses of several hybrid matrices. ${ }^{12}$ Silicon alkoxide precursors undergo sol-gel reactions in several steps with simultaneous hydrolysis and condensation reactions to produce reliable hybrid polymer coatings with varying chemical and mechanical properties for metal protection. ${ }^{13}$ Sol-gel matrices are unique because the presence of colloidal pores enables the successful encapsulation of additives such cells, enzymes, metal-based inhibitors ${ }^{14}$ and bacterial endospores. Adequate choice of the precursor chemistry, reaction conditions and biofilm of inoculums of protective bacteria could produce functionalized hybrid solgels with good aging, stability, shelf life, MIC and fouling inhibition properties. Recent studies ${ }^{15,16}$ have shown that mitigating MIC and biofouling by encapsulating endospores of protective bacteria in the sol-gel coating on metal substrates gives improved corrosion and fouling protection in comparison to sol-gel alone. The concept of MIC inhibition using biofilms of Paenibacillus polymyxa and Pseudomonas fragi within sol-gel matrix has been evaluated to give a novel protective coating for aluminium alloy. ${ }^{15}$ The corrosion inhibition by other sporeforming Gram-positive bacteria have also been widely reported in the literature for many metal substrates in both freshwater and seawater. These microbes alter the rate of metal dissolution as long as they remain viable in the media by reducing the concentration of oxygen at the metal surface via aerobic respiration. For this class of bacteria, the nature of their biofilms have been reported to have huge influences on the overall electrochemical process as a consequence of their metabolic activities. Some biofilm-forming strains of Bacillus brevis and Bacillus subtilis can secrete antimicrobial substances (e.g. gramicidin S antibiotics) in their biofilm thereby preventing the settlement of other bacteria capable of inducing corrosion. ${ }^{17,18}$ Arps et al. ${ }^{19}$ have also reported the corrosion reduction of some steel alloys in an artificial service water using Bacillus strains capable of producing polymyxins and gramicidin $\mathrm{S}$. Amongst the Gram-positive and spore-forming Bacillus species with the potency of reducing metal corrosion is Bacillus licheniformis. Most corrosion inhibiting strains of B. licheniformis are biofilm-forming bacteria capable of secreting antibiotics that can act as corrosion inhibitors. Ornek et al. ${ }^{20}$ have studied pitting corrosion of aluminum 2024 substrate in the presence of B. licheniformis ATCC 9945A strain using in Luria Bertani (LB) medium by electrochemical impedance spectroscopy (EIS). Aluminum pitting corrosion was found to reduce by more than $85 \%$ compared to the sterile controls after a week of continuous exposure in LB medium contained in a bioreactor. Authors attributed this unique bacterial behavior to the secretion $\gamma$ polyglutamate by the bacterial biofilm in the B. licheniformis culture at $\mathrm{pH}>6$. B. licheniformis is an endospore-forming, Gram-positive and motile bacterium with anaerobic activity known to readily adhere to surfaces, and subsequently forming biofilms even at harsh conditions. ${ }^{21}$ Since MIC of steel continues to provide challenges on the industrial application of 
steel, including the choice of a coating system that can provide both anticorrosion and antifouling properties, a thermophilic strain of $B$. licheniformis has been employed to reduce the corrosion rate of mild steel in this study. In this work, an endospore-forming strain of B. licheniformis isolated from Saudi Arabia and two metal-based phosphate and molybdate corrosion inhibitors are encapsulated into the bulk of a newly synthesized amino-epoxy type sol-gel coating for the inhibition of MIC of steel. Protective thermophilic bacteria are common in the hot springs of Saudi Arabian deserts and they possess unique adaptation abilities that permits their survival and existence in the desert climates of the Gulf. The corrosion resistance and antifouling properties of these functionalized coatings are evaluated using laboratory electrochemical impedance spectroscopy and exposure trials in the hyper-saline Saudi Arabian Gulf marine environment.

\section{Experimental}

\subsection{Pre-treatment, reagents and sol-gel formulation method}

The corrosion inhibitors used in this study were zinc aluminium polyphosphate (ZAPP) and zinc molybdate (MOLY) pigments obtained from Heucophos ${ }^{\circledR}$ ZAPP (28.1-31.0\% ZnO) and MOLY-white 101 (85\% $\mathrm{ZnMoO}_{4}$ ) (Heucotech Ltd. Co, US), respectively. The Si-based sol-gel coating was synthesized by blending tetraorthosilicate (TEOS, Sigma-Aldrich, US), 3-glycidoxypropyltrimethoxysilane (GPTMS, Sigma-Aldrich, US) and 6-7\% (aminopropyl methyl siloxane)-dimethylsiloxane copolymer (PDMS-amino, GELEST, US) in a $10: 6: 4$ ratio. The mixture was stirred for an hour and a mixture of $0.5 \mathrm{~mL} 0.05 \mathrm{~N} \mathrm{HNO}_{3}$ (SigmaAldrich, US), $2 \mathrm{~mL}$ water and $4.5 \mathrm{~mL}$ isopropanol (Sigma-Aldrich, US) was then added dropwise at room temperature to induce the hydrolysis-condensation reaction. The sol-gel mixture was stirred continuously and aged for three days then finally coated on steel panels. The $\mathrm{pH}$ of the final coating was 3.4. All precursors involved in the sol-gel reaction were used without further purification. The sol-gel solution prepared above was then doped individually with both ZAPP and MOLY inhibitor by suspending the appropriate inhibitor (to $5 \% \mathrm{w} / \mathrm{v}$ ) into the solution and stirring $(450 \mathrm{rpm}$ ) for 30 minutes, followed by sonication for an hour. These inhibitordoped sol-gel coatings were used as abiotic control matrices, and were labelled as SZ and SM, for each of ZAPP and MOLY, respectively. Table 1 presents the sample coding used for the variants of the inhibitor-doped abiotic coating system.

\subsection{Preparation of Bacillus licheniformis endospore suspension}

The procedures for the isolation and identification of thermophilic strain of Bacillus licheniformis are elaborated in the ESI. $\uparrow^{, 22-27}$ A single colony of the bacterium was used to inoculate a $5 \mathrm{~mL}$ aliquot of tetrathionate (TT) broth and incubated $\left(50{ }^{\circ} \mathrm{C}\right.$, shaking at $180 \mathrm{rpm}$ ) overnight to provide a starter culture, which was used to inoculate the new flask containing fresh media. Endospores were produced from 1 litre aerobic TT culture in 2 liter flask at a constant temperature of $50^{\circ} \mathrm{C}$ with an impeller speed of $200 \mathrm{rpm}$ with an aeration rate of $1.5 \mathrm{~L} \mathrm{~min}^{-1}$. Sporulation and lysis of mother cells were confirmed before harvesting the culture after seven days of growth. Endospores were recovered from the culture by centrifugation $(17700 \times g$ at $4{ }^{\circ} \mathrm{C}$ for ten minutes in $6 \times 500 \mathrm{~mL}$ centrifuge pots) and washed five times with ice-cold water before another centrifugation trial, subsequent addition of sterile water, ice sonication and vortexing with water-saturated chloroform mixture per $\mathrm{mL}$ of endospore suspension. ${ }^{15}$ The endospore suspension was adjusted to an $\mathrm{OD}_{600}$ of 66 with sterile distilled water before storage at $-20{ }^{\circ} \mathrm{C}$. The Bacillus endospore suspension was thawed on ice at room temperature and centrifuged to remove excess chloroform. $1 \mathrm{~mL}$ of the prepared sol-gel was later added to diluted suspension above and sonicated for 5 seconds to separate possible aggregated endospores. Care was taken to avoid excess sonication; structural integrity of endospores was confirmed microscopically after sonication. The sol-gel bacterial/endospore suspension was then added to $10 \mathrm{~mL}$ of sol-gel mixture and labelled as biotic (S6). This was repeated with inhibitor functionalized sol-gel coating, ZAPP and MOLY, respectively, and labelled as SZ6 and SM6. Table $1 \dagger$ presents a descriptive summary of the biotic and abiotic sol-gel coating matrices used in this study. The measured bacterial endospore concentration in the sol-gel solution used throughout this study was $1.98 \times 10^{6} \mathrm{CFU}$ per $\mathrm{ml}$ (CFL per ml). This was evaluated prior to coating by measuring the optical density (OD) at $620 \mathrm{~nm}$ before correlating to cell forming units per millilitre (CFU per $\mathrm{mL}$ ) using eqn (1)..$^{28}$

$$
\text { Concentration }(\mathrm{CFU} \text { per } \mathrm{ml})=\mathrm{OD}_{620 \mathrm{~nm}} \times 472067
$$

\subsection{Confocal fluorescence microscopy}

Confocal scanning laser microscopy was carried out using a Zeiss AxioVision confocal scanning laser microscope using a plan apochromat $\times 64$ oil immersion objective. Fluorescein

Table 1 Descriptive summary of the modified and unmodified coating matrices used in this study

\begin{tabular}{lll}
\hline Coating type & Coating description & Nomenc \\
\hline Abiotic & Sol-gel coating only & (S) \\
& Sol-gel coating functionalized with corrosion inhibitor (ZAPP) & (SZ) \\
& Sol-gel coating functionalized with corrosion inhibitor (MOLY) & (SM) \\
Biotic & Endospores of Bacillus licheniformis thermophilic strain encapsulated within the sol-gel coating & (S6) \\
& S6 matrix further functionalized with ZAPP & (SZ6) \\
& S6 matrix further functionalized with MOLY & (SM6)
\end{tabular}


isothiocyanate (FITC) $(488 \mathrm{~nm})$ and rhodamine $(543 \mathrm{~nm})$ filters were used for images obtained after staining with BacLight ${ }^{\mathrm{TM}}$ Live/Dead staining kit. $1.5 \mathrm{~cm}^{2}$ (approximately) pieces were cut from the panels, immersed in Nutrient Broth No. 2 (NB2) (at $30{ }^{\circ} \mathrm{C}$ for 24 and 48 hours), and stained using the Baclight ${ }^{\mathrm{TM}}$ Live/Dead bacterial viability stain (invitrogen). The Baclight kit contained two DNA-binding fluorescent stains; viable cells are stained with the green fluorescent stain (Syto 9) and non-viable cells were also stained with propidium iodide. The propidium iodide bonded to the negatively-charged DNA to give red fluorescence via the damaged membranes of non-viable cells. Background fluorescence of both stains was seen since the Syto 9 green stain was able to bind to the sol-gel matrix and the propidium iodide red stain bound to the negatively-charged silanol groups within pores in the sol-gel.

\subsection{Coating procedures}

S36 mild steel panels $\left(0.032^{\prime \prime} \times 3^{\prime \prime} \times 5^{\prime \prime}\right)$ were sonicated (VibraCell Sonics and Material INC., US) with doubly distilled water, air-dried, and then stored in a desiccator. The panels were precleaned with absolute ethanol before the coatings were applied. A millilitre of each of the sol-gel matrices (both modified and unmodified) was roller-coated (R K Print-Coat Instruments Ltd, UK) on each pre-treated steel panel and then allowed to cure at room temperature for 48 hours and then at $40{ }^{\circ} \mathrm{C}$ for 24 hours. All the steel panels were coated under a laminar flow hood at room temperature to avoid cross contamination. Before coating, the microstructure of the metal substrate was studied by SEM (U9320A 8500 Field Emission Scanning Electron Microscope (Agilent Technology, UK)) after metal surface polishing (see ESI $\dagger$ ). ${ }^{29}$

\subsection{Electrochemical impedance spectroscopy (EIS) analyses}

A $\pm 10 \mathrm{mV}$ amplitude voltage perturbation of the mild steel corrosion system over a frequency range of $100 \mathrm{kHz}$ to $10 \mathrm{mHz}$ was scanned with an ac signal at open circuit potential $\left(E_{\text {corr }}\right)$ with the steel substrate in the solution of $3.5 \% \mathrm{wt} \% \mathrm{NaCl}$ electrolyte. EIS Nyquist plots were obtained under potentiostatic conditions for the modified and unmodified coated samples using a three-electrode electrochemical cell (Gamry, US). The counter and reference electrodes used were graphite and a standard calomel electrode, respectively, coupled to a Gamry Instrument potentiostat/galvanostat/ZRA (GAMRY 3000, Gamry Instruments, US) corrosion measuring system. EChem Analyst software package 6.0 was used for all the analyses, curve extrapolation, data fitting and simulations.

\subsection{Coating and surface characterization}

The measurement of the static contact angle of the individual coated metal was performed with a contact angle measurement (CAM) instrument DSA30 (KRUSS, Deutsch, Germany) by pendant water drop for three consecutive trails. The thermal behaviour of this new hybrid sol-gel polymer was characterized with a thermogravimetric (TG) analyzer (Perkin-Elmer TGA 7) at $10{ }^{\circ} \mathrm{C} \mathrm{min}{ }^{-1}$ in $\mathrm{N}_{2}$ raised to about $800{ }^{\circ} \mathrm{C} .{ }^{30}$ Surface analytical evaluation of the coating morphology on the metal was performed using the U9320A 8500 Field Emission Scanning Electron Microscope (Agilent Technology, UK) prior to and after two weeks immersion in $3.5 \% \mathrm{NaCl}$ test solution.

\subsection{Field trials at KFUPM beach}

A field trial in a natural corrosive environment was conducted to ascertain the corrosion protection properties of the unmodified and the abiotic and bio-modified coating systems. The edges of the immersed S36 panels were covered with insulation tape leaving only a defined test area for fouling studies. The marine fouling studies were carried out in the hyper-saline seawater of the King Fahd University of Petroleum and Minerals (KFUPM) beach, Half-Moon Bay, Al-Khobar, Saudi Arabia, between March and June, 2015. The temperature, $\mathrm{pH}$ as well as the salinity of the water body (at the point of sample immersion) recorded throughout the period of fouling studies are presented in the ESI (Table S1 $\dagger$ ). This beach is known for its warm coasts and slow moving waves along the Arabian Gulf at all seasons with high fouling activities and salinity (Fig. S2†).

\section{Results and discussion}

\subsection{Sol-gel coating}

The newly synthesized sol-gel coating was made from silicon alkoxide $\left[\mathrm{Si}(\mathrm{OR})_{n}\right]$ undergoing simultaneously hydrolysiscondensation reactions in several steps (eqn (2)). For Dire and Babonneau, ${ }^{31} \mathrm{Si}(\mathrm{OR})_{n}$ acid catalyzed hydrolysis is known to follow the general route:

$$
\mathrm{Si}(\mathrm{OR})_{n}+\mathrm{HOH} \rightarrow \mathrm{Si}(\mathrm{OR})_{n-1}(\mathrm{OH})+\mathrm{ROH}
$$

As anticorrosive coatings on steel, the general aging time, stability and corresponding shelf-life of these functionalized hybrid sol-gel matrices should extend as condensation reactions continue. Associated condensation reactions are directly related to the removal of water and corresponding alcohol from the polymer matrix resulting in the formation of more rigid silica networks ${ }^{32}$ (eqn (3)). The prepared unmodified sol-gel coating in this study was viscous and relatively clear and stable solution with $\mathrm{pH}$ lightly acidic (pH 3.5). It was modified according to the components stated in Table 1 and each matrix was coated on pre-cleaned mild steel substrates; and Fig. S3† displays the appearance of the coated surfaces without mechanical defects.

$$
2 \mathrm{Si}(\mathrm{OR})_{n-1}(\mathrm{OH}) \rightarrow(\mathrm{OR})_{n-1} \mathrm{Si}-\mathrm{O}-\mathrm{Si}(\mathrm{OR})_{n-1}+\mathrm{HOH}
$$

\subsection{Confocal laser scanning microscopy}

To ascertain the viability of the bacterial endospores in the system of coatings and to ensure that they were alive to execute the needed physiological activities, both biotic and abiotic solgel solutions were inoculated in a TT agar plates ${ }^{16}$ (Fig. S4†) as well as coated on glass slides prior to confocal laser scanning microscopy. The use of appropriate fluorescent probes and confocal scanning laser microscopy aided visualization of the 
viable and non-viable vegetative cell distribution within the solgel matrix. Bioactive coated glass samples were immersed in a nutrient solution (NB2 broth) for $24 \mathrm{~h}$ and then stained with the Baclight Live/Dead stain (invitrogen) and incubated to observe cell viability of the endospores, while the abiotic samples were similarly treated and served as negative controls.
Appropriate micrographs were collected with different optical frames as shown in Fig. 1. As the nutrient medium contacts the endospores, bacterial cells are expected to germinate and begin to grow, and this will be accompanied by a change in cell morphology from round/oval (endospores) to rods (vegetative cells). All bioactive coated samples with and without corrosion
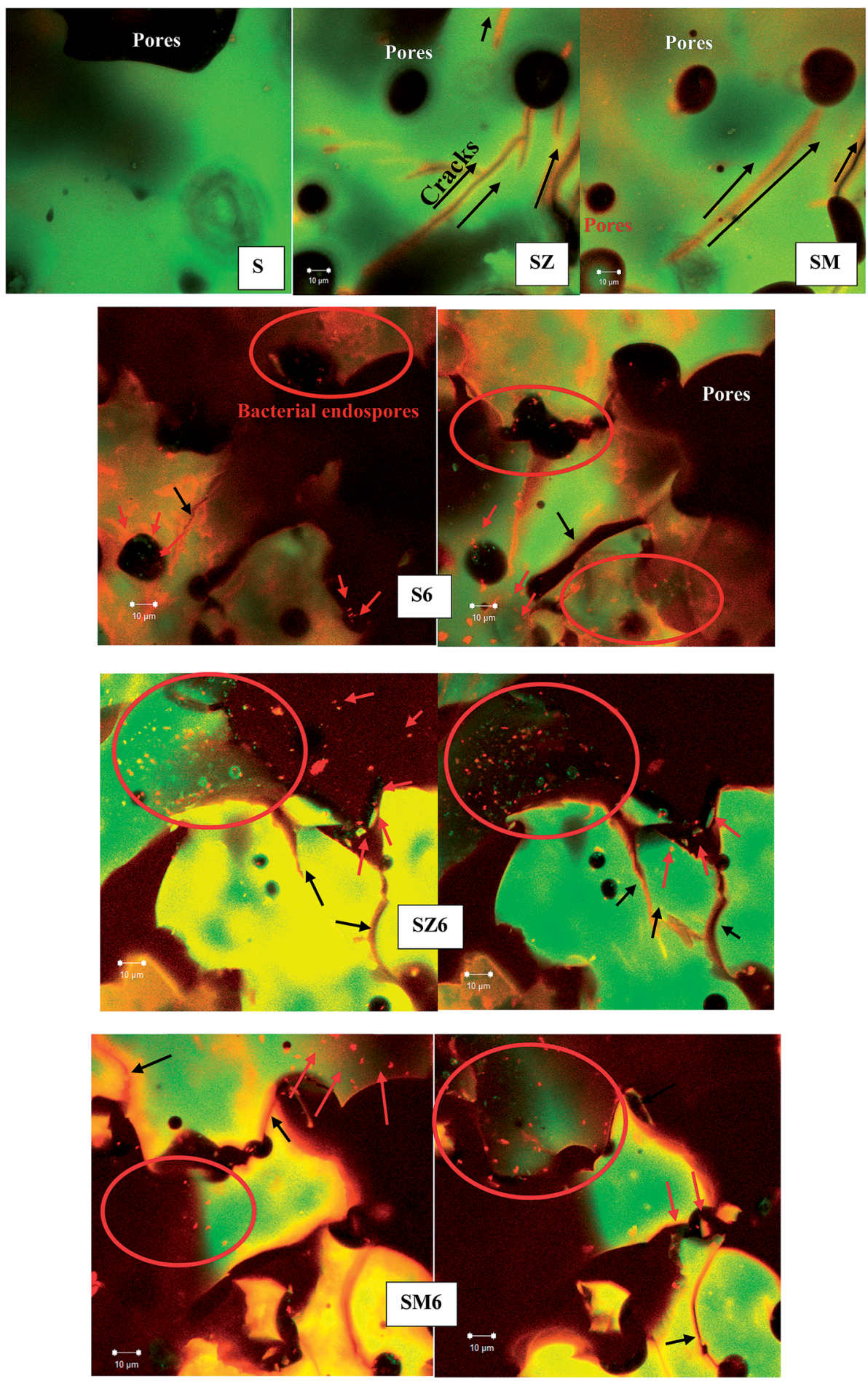

Fig. 1 Confocal fluorescence images showing live cells in the various sol-gel coatings (the black and red bold arrows indicate the cracks and inherent bacterial vegetative cells/endospores, respectively). The stacked confocal images for the bioactive samples are presented in double panels to show clarity. 
inhibitors showed the presence of live (green) and dead (red) endospore- and/or cell-like structures. The predominance of green rod-like cells in the biotic samples indicates viable bacterial cells in the coated samples; and being alive denotes their availability for bioactivity. The cellular clusters observed at this exposure time could be due to formation of biofilms in the early stages of growth. ${ }^{33}$ The characteristic feature of these solgel matrices as shown on the confocal florescence micrographs is the presence of surface cracks and peels caused by poor coating adhesion or coating disbonding on the glass slides. Bulk pores can be seen as dark, round shapes on the micrographs for the abiotic sample. Other than the pores, the abiotic sample (S) has a relatively featureless appearance in comparison to the other coating samples.

The confocal florescence micrographs of the abiotic coating matrices show no vegetative bacterial growth as the absence of live cells confirms that samples S, SZ and SM are actually abiotic. The background (mostly green) fluorescence observed in these images was attributed to autofluorescence of the solgel matrix. The green Syto 9 and red propidium iodide fluorescent probes may have bound to the negatively-charged silanol groups within the sol-gel matrix thereby creating these areas of green and also red fluorescence in the background.

\subsection{Thermal analysis and hydrophobicity evaluation}

Thermogravimetric analysis (TGA) curve (recorded under nitrogen) for the synthesized hybrid sol-gel coating is shown in Fig. 2 below; with weight loss (WL) being observed in few thermal regions. The evaporation of occluded $^{34} /$ physically $^{2}$ adsorbed or less strongly chemically bonded water molecules on the sol-gel matrix occurred between laboratory temperature and $250{ }^{\circ} \mathrm{C}$. The magnitude of weight loss corresponding to decomposition/pyrolysis of the bridging organic groups/chains occurs around $300{ }^{\circ} \mathrm{C}$ and between $580{ }^{\circ} \mathrm{C}$ and $650{ }^{\circ} \mathrm{C} .{ }^{35}$ The differential TG (DTG) curve for this newly synthesized sol-gel coating shows typical nonlinear decomposition temperatures $\left(T_{\mathrm{d}}\right)$ around 330,460 and $570{ }^{\circ} \mathrm{C}$. It is adequate to mention here that the condensation reaction continued even up to thermal

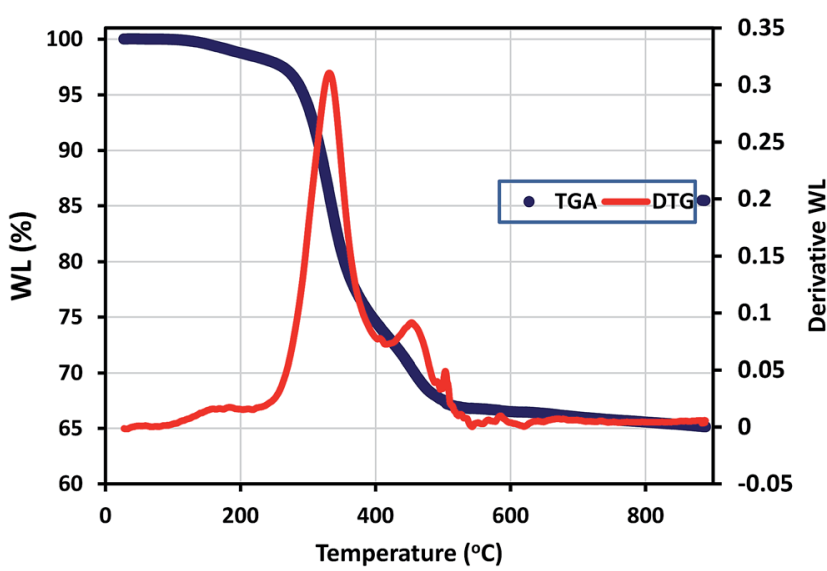

Fig. 2 TG curves of the synthesized hybrid sol-gel (S) coating alone in $\mathrm{N}_{2}$ atmosphere. and curing treatments. To this end, the weight loss observed at elevated temperature could have been due to formation of 3D Si-O-Si network via condensation reactions (above $500{ }^{\circ} \mathrm{C}$ ).

The static water contact angle measurement of abiotic and biotic sol-gel coatings were carried out to evaluate the wetness of their surfaces, and the degree of hydrophobicity of each coating system was deduced from the result. ${ }^{36}$ The results showed that the contact angle of the coatings increased in the following order: $\operatorname{SM6}\left(109^{\circ}\right)>\operatorname{SZ6}\left(95^{\circ}\right)>\operatorname{S6}\left(85^{\circ}\right)>\operatorname{SM}\left(80^{\circ}\right)>$ $\mathrm{SZ}\left(79^{\circ}\right)>\mathrm{S}\left(75^{\circ}\right)$. The sol-gel containing bacterial endospores and MOLY exhibited the most hydrophobic surface $\left(109^{\circ}\right)$; however the reason for this variation has not been investigated in this study (Fig. 3), though B. licheniformis endospores are known to readily form surface-altering biofilms as they secrete antimicrobial substances within these biomaterials. ${ }^{20,21,37,38}$ It can also be observed that the presence of endospores led to an increase in the coating hydrophobicity. Hence, it should be expected that steel panels coated with high contact angle matrices should yield better corrosion protection properties since their surfaces will limit the passage of water molecules as a result of reducing the diffusion rate. The loss in the hydrophobicity of surfaces is an indication of the occurrence of more surface wetting which can lead to the onset of corrosion. ${ }^{36}$

\subsection{Electrochemical impedance spectroscopy (EIS)}

The electrochemical impedance response of all variant coated steel panels immersed in aerated $3.5 \% \mathrm{NaCl}$ solution was recorded periodically for 2 weeks. Comparative Nyquist curves are presented for the different coating systems at immersion periods of 24 hours in Fig. 4(a), 48 hours Fig. 4(b), and 2 weeks Fig. 4(c). The spectra show the presence of multiple time constants, seen as semicircles. These can be attributed to the capacitive and resistive behaviour at high and low frequencies, relating to permeation of electrolyte ions across the coating/ metal interface. The varying inhibition mechanisms for these systems are related to the coating composition for each coated metal. After 24 hours, the impedance responses for the coated systems revealed the first time constant as a capacitive loop,

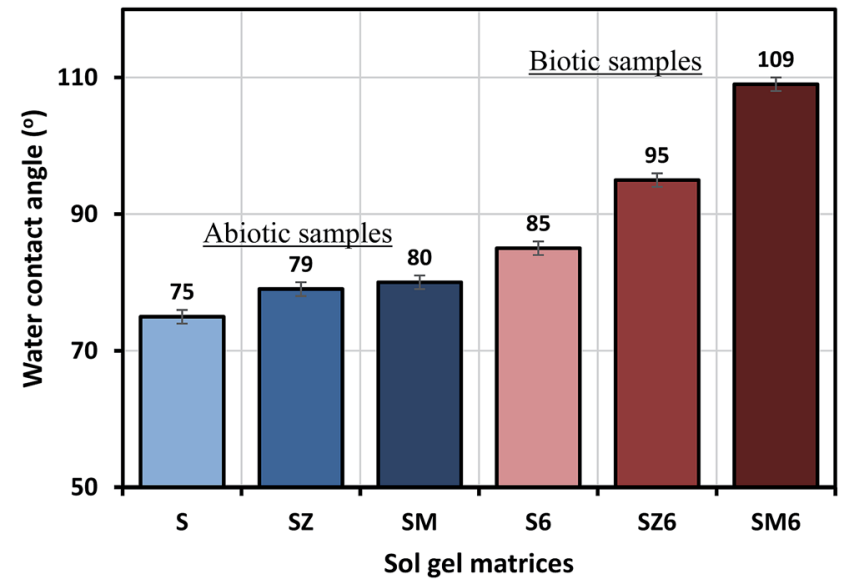

Fig. 3 Contact angle result for steel panels coated with different solgel matrices. 

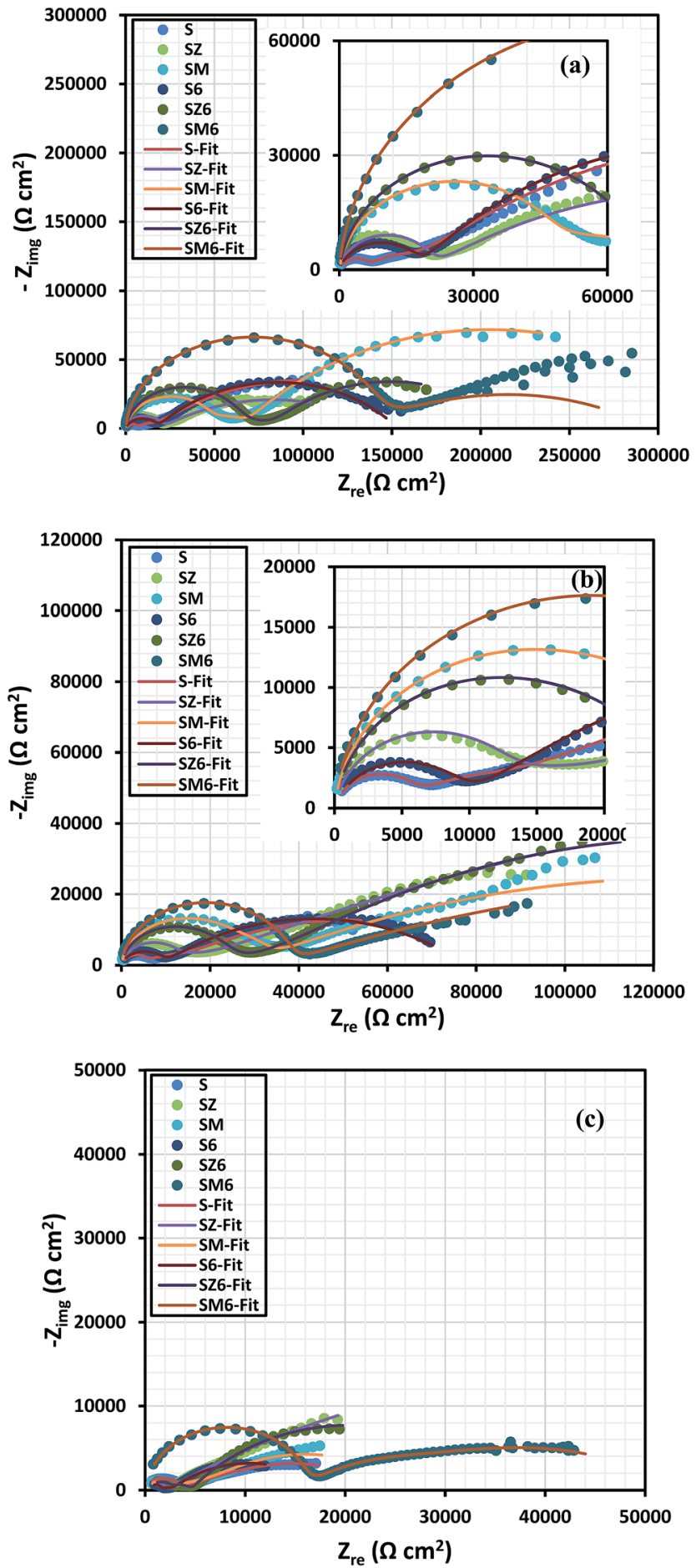

Fig. 4 Nyquist plot of experimental data for all coating matrices after (a) 24 hours (b) 48 hours, and (c) 2 weeks of immersion in $3.5 \mathrm{wt} \% \mathrm{NaCl}$ solution (insert: Nyquist curves showing $Z$ values at higher frequencies).

possibly denoting that the coatings, to some extent, allowed the passage of corrosive chloride ions towards the coating/metal interface. ${ }^{39}$ The size of the Nyquist capacitive semi-circles are generally considered to reflect the degree of protection for each coating system. In Fig. 4 it can be seen, that the presence of MOLY in the coating improved the corrosion protection of steel over that of ZAPP, with and without the bacterial endospores. The presence of the encapsulated endospores in the bulk of the coating appears to increase the impedance of the coating to corrosive chloride ions, with the highest impedance observed for the MOLY-doped coating with the bacterial endospores (SM6). This indicates, in terms of corrosion protection, that there is synergy between the corrosion inhibitors and the $B$. licheniformis endospores. The shapes of the Nyquist curves remain relatively unchanged after $48 \mathrm{~h}$ (Fig. 4(b)) for all the coating systems studied indicating that there must not have been any change in the corrosion protection mechanism on prolonged immersion in the saline electrolyte. SM6 maintains the largest two-time constant $(\gamma)$ capacitive loops after 2 weeks (Fig. 4(c)) showing an outstanding protection against corrosive ions at the steel surface with $\mathrm{S} 6$ being the lesser biotic protective coating. The decrease in the impedance values of the abiotic sol-gel coating alone (S) is due to the failure and disbonding in the coating and subsequent passage of chloride ions to the steel surface. However, the presence of the metal-based corrosion inhibitors continues to improve the protection ability by forming passive films, this is evident from the increased Nyquist semicircles compared to the sol-gel coating alone (Fig. 4(c)). After this prolonged immersion period, there are some distortions in the shapes of the capacitive loops for all the coating systems, though not vividly observed; the most reason constant phase element (CPE) was deployed in the equivalent circuits. These distortions could be directly linked with surface imperfections, such as cracks, and other previously reported interfacial unevenness. ${ }^{40}$

A major factor contributing to the performance of metal-type inhibitors in organic coatings is the relative solubility and stability of the inorganic pigments, and their later availability to initiate passive layer formation at the metal/electrolyte interface. These pigments are known to form precipitates of oxide or/ and hydroxide passive films depending on the chemistry of the metal/electrolyte interface. ${ }^{41-43}$ The electrochemical behaviour of ZAPP has been previously reported to be linked with its critical pigment volume concentration (CPVC) values of 46.3 against 50 for MOLY. ${ }^{39}$ The differences in impedance $(Z)$ indicate that the passage of corrosive ions to the metal surface through the coating was impeded due to an improved interfacial barrier in the presence of these additives. ${ }^{16}$ The actual role of the bacteria, as an anticorrosion agent and their effect on the solubility and kinetic availability of the metal inhibitors, is currently not clear. In order to begin to assess the role of the bacteria it is necessary to determine their behaviour in the system, and in particular whether they form a biofilm and/or metabolic products by these endospores that may influence corrosion, for example by reducing the passage of water and other corrosive ions across the metal/coating interface. However, it is evident in this work that the accumulation of these bacterial endospores increases the surface hydrophobicity, so this further impeded the ionic current flow of corrosive species across the biotic coating, thereby reducing corrosion. Fig. 5 presents the variation of electrochemical impedance $(Z)$, with immersion period, measured at $0.01 \mathrm{~Hz}$. Here the MOLY/bacteria coating shows a higher level of 


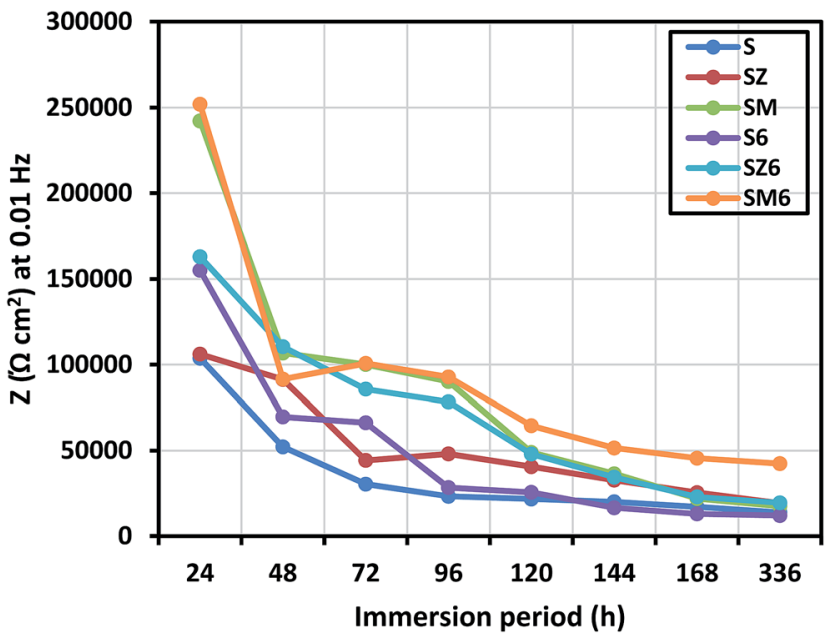

Fig. 5 Impedance values at $0.01 \mathrm{~Hz}$ for all coated samples after 2 weeks of immersion in $3.5 \mathrm{wt} \% \mathrm{NaCl}$ solution.

corrosion protection compared to the other coating systems at the 2 week interval. Overall the other biotic coatings also show slightly higher resistance over the same period.

Echem software is employed in experimental impedance data to the equivalent circuits shown in Fig. $S 5, \dagger$ and the electrochemical parameters derived for the immersion periods under study are listed in the ESI (Table S2 $\dagger$ ). Two-time and three-time constant equivalent circuit models are allotted to respective coating matrices for the fitting and analyzing of the experimental impedance data, with each model selected based on the respective contributions of coating systems at a particular immersion period. Multiple component circuitry with three-time constant (Fig. S5b $\dagger$ ) is proposed for the doped or modified coating at prolonged immersion time (between 72 and 336 days). For both equivalent circuit models, the resistance and constant phase element components of each sol-gel $\left(R_{\text {coat }}\right.$ and $\left.\mathrm{CPE}_{\text {coat }}\right)$ and interfacial $\left(R_{\mathrm{ct}}\right.$ and $\left.\mathrm{CPE}_{\mathrm{dl}}\right)$ layers are being considered, at higher and lower frequencies, respectively. The second constant phase for the equivalent circuit model in Fig. $\mathrm{S} 5 \mathrm{~b} \dagger$ represents the oxide layer $\left(R_{\mathrm{Ox}}\right.$ and $\left.\mathrm{CPE}_{\mathrm{ox}}\right)$. However, in this study, only the trends in $R$ and CPE values corresponding to the first constant phase, being the sol-gel layer, are vividly discussed in a view to showing the direct impact each sol-gel layer on the corrosion protection of the metal substrate in 3.5 $\mathrm{wt} \% \mathrm{NaCl}$. CPE is usually defined as $\mathrm{CPE}=(j \omega)^{-n} / Y_{\mathrm{o}}$; where $n$, $Y_{\mathrm{o}}$ and $\omega$ are the magnitudes of system homogeneity factor, pseudo-capacitance and angular frequency (measured in radian). The CPE components in the circuits relate to a slight deviation of the capacitance from ideality, probably due to a combination of the double layer capacitance, nonhomogeneity of electrode surface and inherent pores in the coating. Fig. 6 displays the changes in the values of $R_{\text {coat }}$ and $\mathrm{CPE}_{\text {coat }}$ with immersion periods for the sol-gel layer of the abiotic (a) and biotic (b) coatings as proposed in the equivalent circuit models. The values of $R_{\text {coat }}$ for S, SZ and SM are 5.6, 19.9 and $52.6 \mathrm{k} \Omega \mathrm{cm}^{2}$, respectively, at the first day (24 hours) of immersion in $3.5 \mathrm{wt} \% \mathrm{NaCl}$ solution (Fig. 6(a)), magnitude of which decreases steadily with exposure time with $5 \mathrm{k} \Omega \mathrm{cm}^{2}$ recorded for the SZ and SM after two weeks (336 days). The reduction in the values of $R_{\text {coat }}$ indicates degradation of coating for S, while the leaching of inhibitor pigments from the bulk of
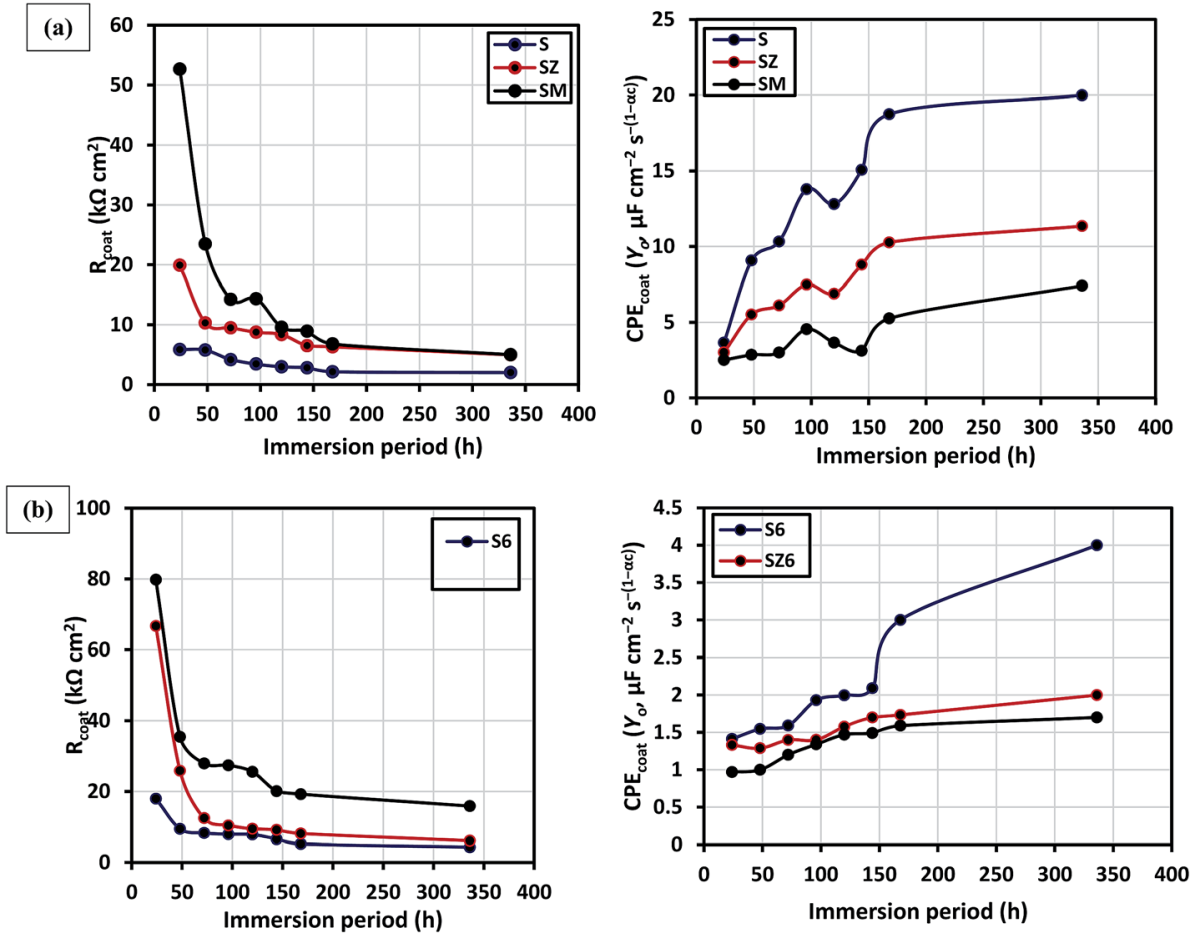

Fig. 6 Variation in sol-gel resistances and capacitances with immersion period for abiotic (a) and biotic (b) sol-gel coatings in 3.5 wt\% $\mathrm{NaCl}$. 
modified matrices (SZ and SM) occurs as the corrosive electrolyte ions reach through the sol-gel layer via created pores inherent the coatings as they gradually deteriorates in $\mathrm{NaCl}$. In the same vain for the biotic coating, values of $R_{\text {coat }}$ are found to decrease sharply between the $24^{\text {th }}$ and 48 th hours, and varies slightly between the third $(72 \mathrm{~h})$ and the seventh $(168 \mathrm{~h})$ day. The recorded values of $R_{\text {coat }}$, as presented in Fig. 6(b), for the biotic coating are greater than the abiotic coating. At 24 hours of immersion, 17.9, 66.7 and $79.8 \mathrm{k} \Omega \mathrm{cm}^{2}$ are recorded for S6, SZ6 and SM6, respectively, while magnitudes of 6.0, 6.1 and $15.9 \mathrm{k} \Omega$ $\mathrm{cm}^{2}$ are observed for this same set of coatings after two weeks of immersion in $3.5 \% \mathrm{NaCl}$ solution. The inherent pores and micro-cracks in the respective sol-gel silica networks allow for free pathways for water and corrosive ions to the surface of the metal substrate, and this could be reason for the steady decrease in the magnitude of sol-gel resistance. The biotic coatings functionalised with inhibitors (SZ6 and SM6) possess a double layer structure, and their greater coating resistance properties compared to the abiotic coating could be attributed to their increased multi-layered hydrophobic interface properties after endospore encapsulation. Generally, the interfacial electrolyte/water absorption (or simply water ability) and bulk coating degradation are hugely defined by the magnitude of coating capacitance.

Fig. 6 (right panel) displays the variation in the values $\mathrm{CPE}_{\text {coat }}$ (measured in $\mu \mathrm{F} \mathrm{cm}^{-2} \mathrm{~s}^{-(1-\alpha c)}$ ) with immersion periods for the abiotic (a) and biotic (b) coatings. For both sets of coatings, abiotic and biotic, higher values of $\mathrm{CPE}_{\text {coat }}$ are recorded for less protective coating matrices representing high rate of water uptake as the exposure time of the coating increases. Magnitude of $\mathrm{CPE}_{\text {coat }}$ for biotic coating are lesser than their abiotic counterpart for all the immersion periods in this study, and $\mathrm{CPE}_{\text {coat }}$ for both sets of coatings are observed to steadily increase with immersion period. For the biotic coating, values of $\mathrm{CPE}_{\text {coat }}$ are ranged between 0.97 to $1.4 \mu \mathrm{F} \mathrm{cm}^{-2} \mathrm{~s}^{-(1-\alpha c)}$ and 1.7 to $4.0 \mu \mathrm{F} \mathrm{cm}^{-2} \mathrm{~s}^{-(1-\alpha c)}$ for the first day and second week of immersion; and between 2.8 to $9.1 \mu \mathrm{F} \mathrm{cm}^{-2} \mathrm{~s}^{-(1-\alpha c)}$ and 7.4 to $19.9 \mu \mathrm{F} \mathrm{cm}^{-2} \mathrm{~s}^{-(1-\alpha c)}$ for the abiotic coating for the same period. Poor water uptake ability of a coating denotes greater protective strength against corrosion, and the sol-gel coating encapsulated with the $B$. licheniformis endospores have shown greater corrosion inhibition in this order: SM6 $>$ SZ6 $>$ S6. The coating homogeneity factor of each coating did not vary much for each coating (around 0.9) while the magnitude of the "goodness of fit" for the fitted experimental data were less than $10^{-3}$.

\subsection{Surface analysis}

Representative SEM micrographs for both abiotic and biotic systems, before and after immersion in $3.5 \mathrm{wt} \% \mathrm{NaCl}$ are displayed in Fig. 7(A) and (B). The sol-gel coating morphology is characterized by the presence of non-uniformly finely dispersed colloidal silica particles in the matrix (labelled with black bold arrows). After 2 week immersion in $3.5 \mathrm{wt} \% \mathrm{NaCl}$, non-uniform cracks are observed for the abiotic (S) coating; this is reflected in the recorded decreased $Z$ values after prolonged immersion. There are visible cracks of the surface of these coating (Fig. 7(A)) after 2 weeks immersion in $3.5 \mathrm{wt} \% \mathrm{NaCl}$. The cause of cracks and other mechanical faults (labelled with blue dashed arrows) observed on the coated metals after prolonged immersion could be linked with the electrolyte, as well as failed adhesion. ${ }^{44,45}$ The presence of surface micro-cracks leads to passage of the corrosive electrolyte to the steel and consequently localised corrosion takes place. However, the presence of the Bacillus endospores greatly improved the corrosion inhibition of the coating in combination with the metal inhibitors. The MOLY functionalized endospore loaded coating had fewer cracks in comparison with other coatings after 2 weeks immersion in the saline solution; the delaminated portion observed on the S6 could be attributed to adhesion failure (Fig. 7(B)). There was no noticeable damage on the bioactive coating system after immersion at room temperature in the aggressive saline test solution. This demonstrates a significant corrosion protection in the presence of the bacterial endospores compared to the abiotic coating. The presence of zinc and molybdate ions from the inhibitor pigments have been confirmed using EDX. The composition of these pigments obtained from EDX analysis were mainly $\mathrm{Si}$ (65.0\%), Zn (0.9\%) and Mo (0.9\%) for SM and Si (38.2\%), Zn (7.6\%) for SZ (see Fig. S6†).

This further proves that the incorporation of these inhibitor pigments into the bulk of coating was successful. Mousavifard et al. ${ }^{39}$ have reported formation of passive films in the present of $\mathrm{Zn}^{+2}$ ions from ZAPP/ZAP inhibitors as the reason for the reduction in metal corrosion. The dissociated $\mathrm{Zn}^{2+}$ prevents the formation of excess $\mathrm{OH}^{-}$ions (eqn (4)) and other associated cathodic reactions at the metal/coating interface; this could be typical of zinc aluminium polyphosphate (ZAPP) and zinc molybdate (MOLY) inhibitors, pigments with common $\mathrm{Zn}^{+2}$ cation.

$$
\mathrm{Zn}^{2+}+2 \mathrm{OH}^{-} \rightarrow \mathrm{Zn}(\mathrm{OH})_{2} \downarrow
$$

The presence of this passive intact oxide layer reduces the interfacial bond underneath the coating upon exposure to corrodent, and this may result in coating disbondment. ${ }^{39}$

\subsection{Field trial in the marine environment}

Labelled coated steel panels were submerged continuously in a natural marine environment in order to study the anticorrosive/antifouling properties of these coatings at KFUPM beach, Half Moon Bay in Saudi Arabia for 10 weeks. The flow of seawater in the Eastern Province of Saudi Arabia is minimal and known for its marine macro-fouling activities and high salinity, a trait of all Gulf sea tributaries in the Sahara. For Half-Moon Bay (KFUPM Beach), the measured salinity values stood at 65.8-71.2 ppt between March and June 2015; this body of water could be classified as being "hyperhaline". Prior to sample immersion, the edges of the panels were covered with insulating tape to prevent corrosion and other oxidation processes, and also to ensure that only the indeed the test area of each substratum was submerged. Evidence of macro-fouling by attachment of foulants are observed by visual inspection. Fig. 8 shows the appearance of the various (A) abiotic and (B) biotic coated panels, in duplicates, after every two week interval for ten 

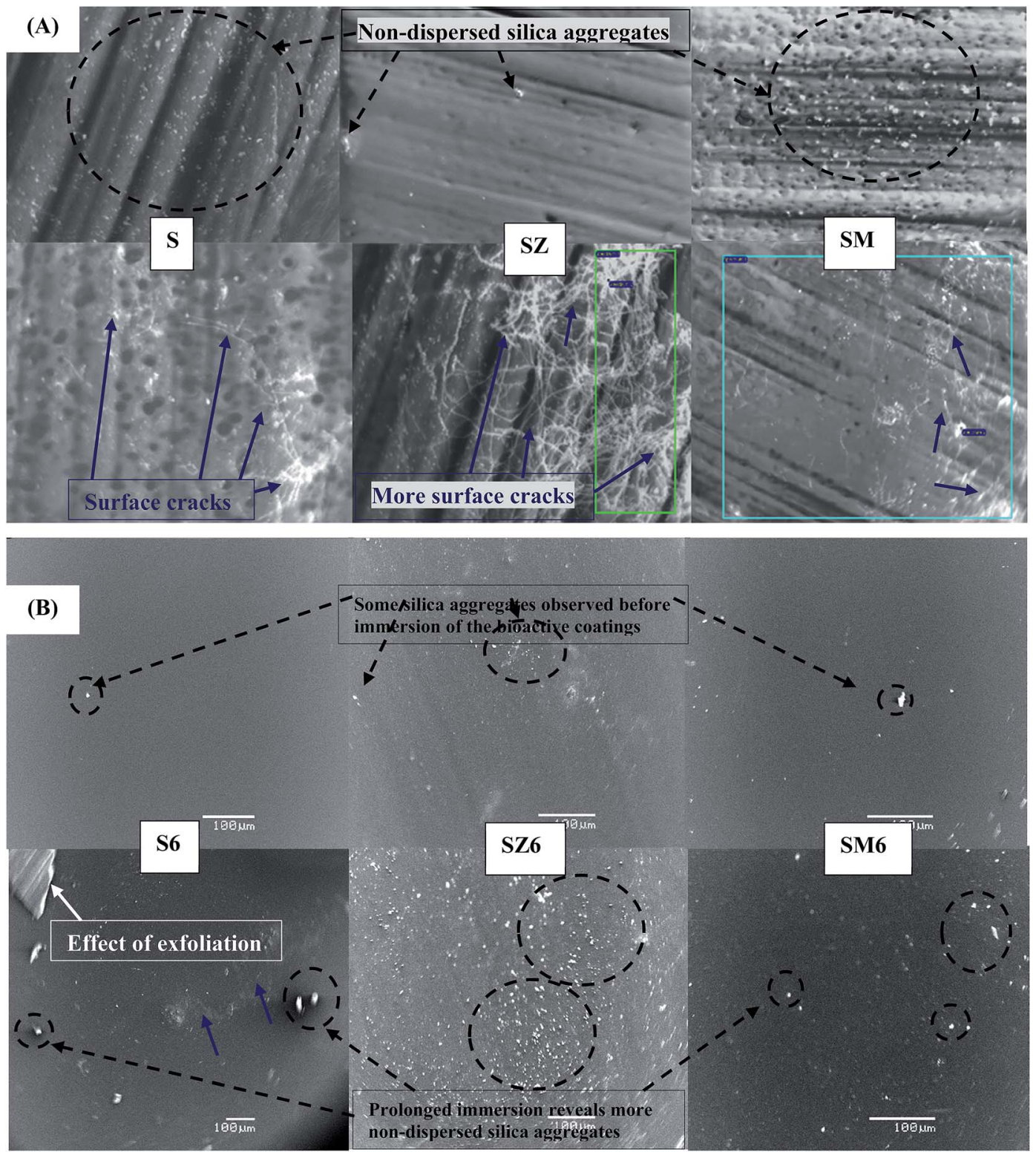

Fig. 7 SEM micrographs of (A) biotic and (B) sol-gel coated steel coupons before (the above panel) and after (the below panel) 2 weeks immersion in $3.5 \mathrm{wt} \% \mathrm{NaCl}$ solution at room temperature [blue and black (dashed) bolded arrows show surface cracks and gel particles, respectively, on the coated substrates]. Fig. $\mathrm{S} 2 \uparrow$ shows more clear micrographs for the abiotic coatings with scale bars.

weeks. An instant corrosion of the bare steel panel is observed immediately after immersion of the panels in the sea water, but not on the coated samples. Both the abiotic and the biotic solgel coated samples gradually decolorized and appeared dull on prolonged exposure in the saline sea water. Images collected for both sets of coatings during the earlier weeks proved that it was too early to assess corrosion and fouling phenomena. Normally for some biofouling organisms, their initial settlement on any substratum is highly influenced by the surface chemistry and topology, nutrient availability and rheology/hydrodynamics; environmental factors of which subsequent fouling population dynamics and community structure are being affected. Images of the abiotic coated panels in Fig. 8(A) display episodes of surface pitting observed on the sol-gel coatings after two week, and this developed into severe delamination of the coatings in the proceeding weeks as fouling increases. The observed surface delamination must also have been initiated by the physical contact of the coated surfaces with sea debris (not limited to sand grains, sticks and stones) inherent in the flowing sea water which is typical of KFUPM beach. Among abiotic samples, the coating with ZAPP pigments (SZ) seems to retain a relatively clear surface appearance throughout the period of study, yet the coating failed at the $8^{\text {th }}$ week; both inhibitormodified coatings (SZ and SM) demonstrated better anticorrosion behaviour compared to the unmodified coating (S) throughout the duration of the field experiment. The properties of these inhibitor (pigment)-doped coatings could be attributed to the stability of chemical species that acted as passive films 

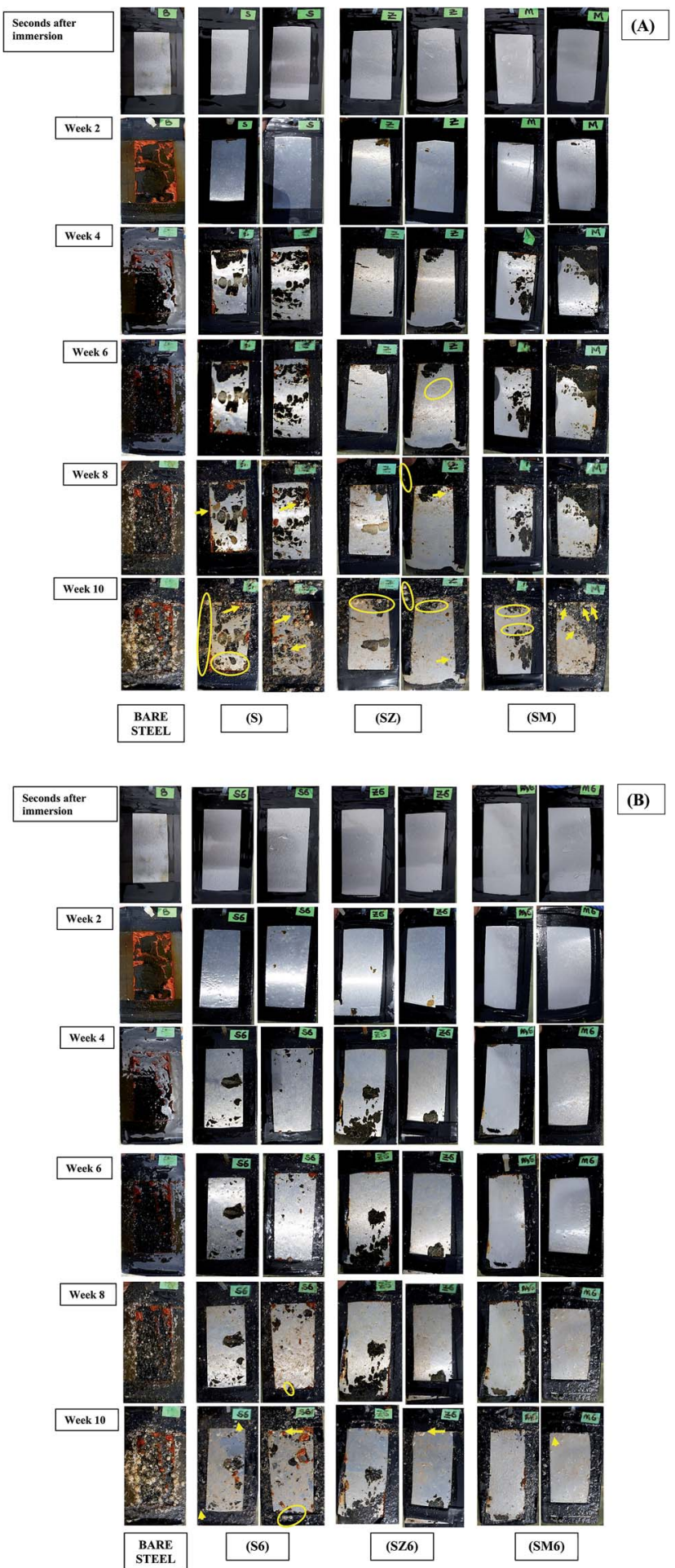

Fig. 8 Field trial samples in duplicates: (A) abiotic and (B) biotic coated steel panels compared with bare/uncoated steel.

thereby impeding anodic and/or cathodic reactions at the metal/solution interface. Pigment types and their product solubility, as well as their stability determines the possibility of bulk leaching from the coating. At the $8^{\text {th }}$ week, newly metamorphosed juvenile barnacles are observed on the delaminated sections of the coated steel panels which later developed into full-grown hard-shelled barnacle after at the $10^{\text {th }}$ week; they are also attached on the black insulating tape covering the edge (circles and arrows). A comparative attempt to understand the effect of inoculums of protective thermophilic strain of $B$. licheniformis endospores on the antifouling as well as the anticorrosive of this sol-gel type coating of steel has been evaluated in the same marine condition with those of the abiotic coatings. Fig. 8(B) presents duplicates photodigital images after ten weeks immersion for the biotic coated steel panels compared with bare/uncoated steel. The congested fouling population on the bare steel reveals an assemblage of annelid-type polychaetes and large growing hard-shelled barnacles vivid between the $6^{\text {th }}$ and $10^{\text {th }}$ weeks; barnacles appear as newly metamorphosed juveniles after the $4^{\text {th }}$ week. The integrity of the biotic coatings is still intact compared to their abiotic counterpart in terms of corrosion and surface pitting; surface delamination is pronounced only after the $4^{\text {th }}$ week. For the biotic coating without inhibitors (S6), biofouling is only vividly observed at the $10^{\text {th }}$ week, with the endospore-loaded coatings with inhibitor (SZ6 and SM6) having improved antifouling and anticorrosion properties. At the $10^{\text {th }}$ week, it is evident that the biotic coating demonstrated the best corrosion/fouling resistance compared to the abiotic coating. In all, the assessment of marine fouling results reveals that the protective bacterial endospores encapsulated into the sol-gel coatings demonstrate potential for antifouling activity and corrosion protection within the duration and conditions of study. The reason for the antifouling potential of these bioactive coatings could be linked with their antibiotic-type hydrophobic surfaces due to the accumulation of $B$. licheniformis endospores widely reported to secrete antimicrobial $\gamma$-polyglutamate from their biofilms..$^{20,37,38}$ The antifouling properties of these coating matrices could be further improved and made longer-lasting by varying the density of the $B$. licheniformis endospores in the coating, moderating the curing period of the coating on the steel and by optimizing other surface post-treatment procedures; a future plan of this research group.

\subsection{Proposed mechanism of bacterial anticorrosion and antifouling activity}

The experimental result obtained from this research concept could be further explained in Scheme 1 below; where the settlement and subsequent adhesion of marine foulers at the surface of the protective coating is impeded by the presence of thermophilic bacterial endospores by foul-releasing mechanism. This bioactive coating simultaneously prevents metal corrosion and foul adhesion compared to the abiotic coatings, while the bare steel substrate is heavily corroded and fouled.

Since the accumulation of viable $B$. licheniformis endospores in the sol-gel coating has evidently increased surface hydrophobicity, the impedance of ionic current of corrosive species at the surface of the coating is enhanced, hence corrosion is mitigated. However, the reduction in coating resistance with prolonged exposure period reveals that permeability of these corrosive ions via conductive pathways and bulk pores on the coating must be due to coating degradation and the leaching 


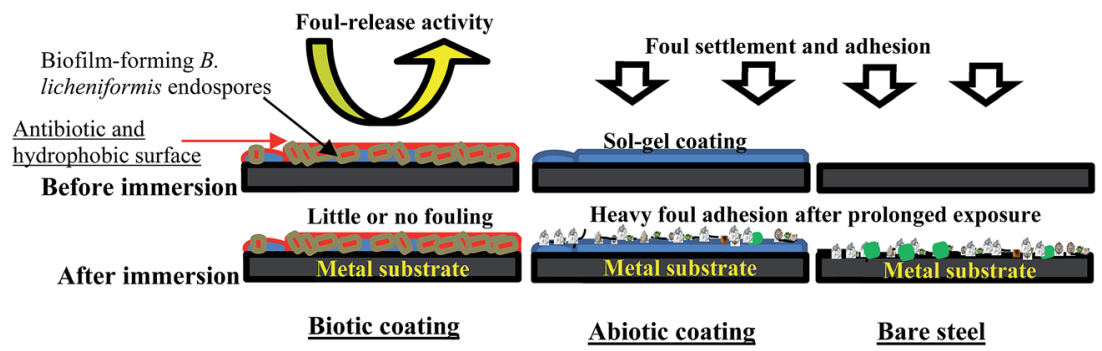

Scheme 1 Foul-releasing mechanism in the presence of the endospores of thermophilic $B$. licheniformis strain in the sol-gel coating involves surface resistance towards foul settlement and adhesion due to the formation of bacterial biofilm with an antibiotic character.

out of active coating ingredients (in this case, the bacterial endospores and corrosion inhibitors). This reduce surface wetness in the presence of the bacterial endospores could have been due to the secretion an antimicrobial type substance within their biofilms that disallowed corrosion as well as the settlement and adhesion of marine foulers. B. licheniformis is widely reported to freely secrete large amounts of anticorrosive $\gamma$-polyglutamate ( $\gamma$-PGM) from its biofilm into growth media as long as it is viable and alive. ${ }^{20,37,38,46-48}$ The secreted $\gamma$-PGM is a homopolymer of glutamic acid characterized structurally by amide linkages between $\alpha$-amino and $\gamma$-carboxyl functional groups of the glutamate moiety. It is known be produced between 5 and $23 \mathrm{~g} \mathrm{~L} \mathrm{~L}^{-1}$ in any B. licheniformis culture, depending on $\mathrm{pH}$ and the availability of nutrients. ${ }^{20,37}$ B. licheniformis is one of the numerous Bacillus sp. whose biofilm has been reported to secrete extracellular antibiotic polymeric substances with corrosion inhibiting potentials like $\gamma$-PGM. ${ }^{38}$ Ornek et al. ${ }^{20}$ electrochemically studied aluminum pitting corrosion in a LB medium inoculated with $B$. licheniformis ATCC 9945A strain. The reduction of aluminum pitting in this medium was attributed to the secretion $\gamma$-PGM by the bacterial biofilm, with $85 \%$ reduction efficiency observed compared to the sterile control in the same medium.

\section{Conclusions}

The following conclusions are drawn from the trend of experimental results:

1. The unmodified sol-gel coating synthesized in this work has protected mild against corrosion to a great extent in $3.5 \mathrm{wt} \%$ $\mathrm{NaCl}$ solution; but improved protection was realised after doping with two zinc-based corrosion inhibitor pigments and $B$. licheniformis endospores.

2. Thermophilic strain of B. licheniformis endospores isolated from the Gazan hot springs of Saudi Arabia encapsulated within the sol-gel matrix remained viable as revealed by the confocal laser scanning fluorescence microscopy. The presence of these bacterial endospores improved the surface hydrophobicity of the coating thereby preventing the diffusion of corrosion molecules and ions through the bulk of the coating to the metal surface; this is evident in the trend of electrochemical coating resistance and capacitance.

3. SEM micrographs shows no noticeable damage for the endospores-loaded sol-gel coatings after 2 weeks immersion at room temperature in $3.5 \mathrm{wt} \% \mathrm{NaCl}$ solution, and this demonstrates significant corrosion protection in the presence of the bacterial endospores compared to the abiotic coatings. The poor performance of the inhibitor-loaded coating could be ascribed to the presence of micro-cracks within the coating.

4. The bacterial endospores possess antifouling potentials within the immersion period of study due to their foul-releasing effect; the improved corrosion and fouling resistance in the presence of these bacterial endospores could be attributed to surface hydrophobicity after spore encapsulation. Compared with the abiotic coating, the inability of the marine foulers to settle and adhere on this biotic surface, at hypersaline condition (65.8-71.2 ppt), gives an idea of its antibiotic nature and the antimicrobial properties of the biofilm of this unique thermophilic bacterium.

\section{Acknowledgements}

The authors would like to acknowledge KFUPM for funding the research work, conducted within the SHU-KFUPM collaborative research agreement, and the EPSRC for funding the underpinning research work. The authors would also like to thank the University of Manchester for providing support to this study.

\section{References}

1 S. J. Yuan and S. O. Pehkonen, Colloids Surf., B, 2007, 59, 8799.

2 S. K. Wieczorek and C. D. Todd, Biofouling, 1998, 12, 81-118.

3 Y. K. Demirel, M. Khorasanchi, O. Turan, A. Incecik and M. P. Schultz, Ocean Eng., 2014, 89, 21-31.

4 L. D. Chambers, J. A. Wharton, R. J. K. Wood, F. C. Walsh and K. R. Stokes, Prog. Org. Coat., 2014, 77, 473-484.

5 J. E. Gittens, T. J. Smith, R. Suleiman and R. Akid, Biotechnol. Adv., 2013, 31, 1738-1753.

6 M. A. Champ, Sci. Total Environ., 2000, 258, 21-71.

7 D. Berto, M. Giani, R. Boscolo, S. Covelli, O. Giovanardi, M. Massironi and L. Grassia, Mar. Pollut. Bull., 2007, 55, 425-435.

8 M. Berglin, K. J. Wynne and P. Gatenholm, J. Colloid Interface Sci., 2003, 257, 383-391.

9 R. Quintana, D. Jaczewski, V. A. Vasantha, S. Jana, S. S. C. Lee, F. J. Parra-Velandia, S. Guo, A. Parthiban, 
S. L.-M. Teo and G. J. Vancso, Colloids Surf., B, 2014, 120, 118-124.

10 W. J. Yang, K.-G. Neoh, E.-T. Kang, S. L.-M. Teo and D. Rittschof, Prog. Polym. Sci., 2014, 39, 1017-1042.

11 M. Carman, T. Estes, A. Feinberg, J. Schumacher, W. Wilkerson, L. Wilson, M. Callow, J. Callow and A. Brennan, Biofouling, 2006, 22, 11-21.

12 D. Wang and G. R. Bierwagen, Prog. Org. Coat., 2009, 64, 327338.

13 K. A. Yasakau, J. Carneiro, M. L. Zheludkevich and M. G. S. Ferreira, Surf. Coat. Technol., 2014, 246, 6-16.

14 H. Shi, F. Liu and E.-h. Han, Prog. Org. Coat., 2009, 66, 183191.

15 R. Akid, H. Wang, T. J. Smith, D. Greenfield and J. C. Earthman, Adv. Funct. Mater., 2008, 18, 203-211.

16 J. Gittens, H. Wang, T. J. Smith, R. Akid and D. Greenfield, in Fifth International Symposium on Advances in Corrosion Protection by Organic Coatings, ed. M. Kendig and D. Scantlebury, 2010, pp. 211-229.

17 R. Zuo and T. K. Wood, Appl. Microbiol. Biotechnol., 2004, 65, 747-753.

18 A. Jayaraman, F. B. Mansfeld and T. K. Wood, J. Ind. Microbiol. Biotechnol., 1999, 22, 167-175.

19 P. J. Arps, J. C. Earthman, L. C. Xu and B. C. Syrett, CORROSION/03, NACE International, San Diego, CA, 2003, Paper no. 03714.

20 D. Ornek, A. Jayaraman, B. C. Syrett, C. H. Hsu, F. B. Mansfeld and T. K. Wood, Appl. Microbiol. Biotechnol., 2002, 58, 651-657.

21 S. G. Batrakov, T. A. Rodionov, S. E. Esipov, N. B. Polyakov, V. I. Sheichenko, N. V. Shekhovtsov, S. M. Lukin, N. S. Panikov and Y. A. Nikolaev, Biochim. Biophys. Acta, 2003, 1634, 107-115.

22 M. A. Khiyami, E. A. Serour, M. M. Shehata and A. H. Bahklia, Afr. J. Biotechnol., 2012, 11, 4053-4062.

23 R. M. M. Abed, A. Al-Thukair and D. de Beer, FEMS Microbiol. Ecol., 2006, 57, 290-301.

24 Z. A. Mohamed, Toxicon, 2008, 51, 17-27.

25 A. Khalil, Afr. J. Biotechnol., 2011, 10, 8834-8839.

26 P. Miquel, Monographie d'un bacille vivant au-dela de $70{ }^{\circ} \mathrm{C}$, Ann Micrographic, 1888, 1, 3.

27 A. Khalil, G. Anfoka and S. Bdour, World J. Microbiol. Biotechnol., 2003, 19, 239-241.
28 M. Mehanna, R. Basséguy, M. L. Délia and A. Bergel, Corros. Sci., 2009, 51, 2596-2604.

29 M. M. Solomon, S. A. Umoren and E. J. Abai, J. Mol. Liq., 2015, 212, 340-351.

30 F. Mansfeld, Electrochim. Acta, 2007, 52, 7670-7680.

31 S. Dire and F. Babonneau, J. Non-Cryst. Solids, 1994, 167, 2936.

32 C. M. Sanchez, B. Julian, P. Belleville and M. Popall, J. Mater. Chem., 2005, 15, 3559-3592.

33 N. D. Vejar, M. I. Azocar, L. A. Tamayo, E. Gonzalez, J. Pavez, M. Gulppi, J. H. Zagal, X. Zhou, F. Santibaez and G. E. Thompson, Int. J. Electrochem. Sci., 2013, 8, 1206212077.

34 D. Tronelli, E. Maugini, F. Bossa and S. Pascarella, FEBS J., 2007, 274, 4595-4608.

35 M. A. Wahab, W. Guo, W.-J. Cho and C.-S. Ha, J. Sol-Gel Sci. Technol., 2003, 27, 333-341.

36 H. Jeon, J. Park and M. Shon, J. Ind. Eng. Chem., 2013, 19, 849-853.

37 Y. H. Ko and R. A. Gross, Biotechnol. Bioeng., 1998, 57, 30437.

38 K. A. Zarasvand and V. R. Rai, Int. Biodeterior. Biodegrad., 2014, 87, 66-74.

39 S. M. Mousavifard, P. M. Nouri, M. M. Attar and B. Ramezanzadeh, J. Ind. Eng. Chem., 2013, 19, 1031-1039.

40 S. A. Umoren, Y. Li and F. H. Wang, Corros. Sci., 2010, 52, 1777-1786.

41 R. Naderi, M. Mahdavian and M. M. Attar, Electrochim. Acta, 2009, 54, 6892-6895.

42 A. Kalendova, Anti-Corros. Methods Mater., 2003, 50, 82-90.

43 L. Mascia, L. Prezzi, G. D. Wilcox and M. Lavorgna, Prog. Org. Coat., 2006, 56, 13-22.

44 A. S. Hamdy, D. P. Butt and A. A. Ismail, Electrochim. Acta, 2007, 52, 3310-3316.

45 S. Peng, W. Zhao, Z. Zeng, H. Li, Q. Xue and X. Wu, J. Sol-Gel Sci. Technol., 2013, 66, 133-138.

46 D. Ornek, T. K. Wood, C. H. Hsu, Z. Sun and F. Mansfeld, Corrosion, 2002, 58, 761-767.

47 D. Ornek, T. K. Wood, C. H. Hsu and F. Mansfeld, Corros. Sci., 2002, 44, 2291-2302.

48 F. Mansfeld, H. Hsu, D. Ornek, T. K. Wood and B. C. Syrett, J. Electrochem. Soc., 2002, 149, B130-B138. 